\title{
Numerical and Experimental Study of Ti6Al4V Components Manufactured Using Powder Bed Fusion Additive Manufacturing
}

\author{
JONAS ZIELINSKI, ${ }^{1,3,4}$ HANS-WILFRIED MINDT, ${ }^{2}$ JAN DÜCHTING ${ }^{3}$ \\ JOHANNES HENRICH SCHLEIFENBAUM, ${ }^{1,3}$ \\ and MUSTAFA MEGAHED $\mathbb{1}^{2,5}$
}

\begin{abstract}
1.-RWTH Aachen University - Digital Additive Production, Aachen, Germany. 2.-ESI Group, Essen, Germany. 3.-Fraunhofer Institute for Laser Technology, Aachen, Germany. 4.-e-mail: Jonas.Zielinski@DAP.Rwth-Aachen.de.5.—e-mail: mme@esi-group.com
\end{abstract}

\begin{abstract}
Powder bed fusion additive manufacturing of titanium alloys is an interesting manufacturing route for many applications requiring high material strength combined with geometric complexity. Managing powder bed fusion challenges, including porosity, surface finish, distortions and residual stresses of as-built material, is the key to bringing the advantages of this process to production main stream. This paper discusses the application of experimental and numerical analysis towards optimizing the manufacturing process of a demonstration component. Powder characterization including assessment of the reusability, assessment of material consolidation and process window optimization is pursued prior to applying the identified optima to study the distortion and residual stresses of the demonstrator. Comparisons of numerical predictions with measurements show good correlations along the complete numerical chain.
\end{abstract}

\section{INTRODUCTION}

Additive manufacturing is a versatile manufacturing route promising shorter lead times for complex and personalized functional products. The process flexibility and strength originates from the use of many control parameters ${ }^{1}$ and comes at the cost of high nonlinearity of the system. Qualifying additive manufacturing processes and asserting product quality is coupled with extensive experimental effort. To reduce experimental cost, physicsbased modeling is expected to offer more insight and enable virtual optimization while providing the necessary documentation for expected material and product qualification. ${ }^{2}$

This paper focuses on the application of a modeling platform encompassing powder-scale models as well as component-scale models towards assessing the final quality of a demonstrator component. ${ }^{3-7}$ Ti6Al4V is chosen to demonstrate the modeling work flow. The numerical results of each step are compared to experimental measurements confirming the applicability of numerical methods towards quick economic qualification of additive manufactured parts. ${ }^{2}$

\section{EXPERIMENTS}

\section{Powder Bed Fusion Machine}

For the single-track experiments, an EOS M270 and an ILT laboratory machine have been used. The manufacturing of the distortion specimens and the melt pool monitoring was performed on the latter. One of the important differences between the two machines is their laser beam diameter $\left(d_{\mathrm{L}}\right)$.

\section{Single Tracks studies}

Melting has been investigated by varying the line energy $E_{\mathrm{L}}=P_{\mathrm{L}} / v_{\mathrm{S}}$ (where $P_{\mathrm{L}}$ is laser power and $v_{\mathrm{S}}$ is scan speed) in such a way, that a transition from a 'heat conduction'-dominated process towards a 'keyhole'-dominated ${ }^{8}$ process is observed (Fig. 1). We have also investigated the influence of different laser beam diameters on the melt pool geometry. 
(a)

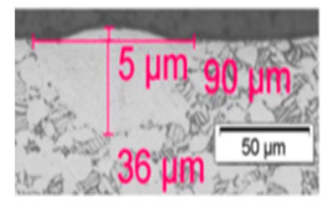

(b)

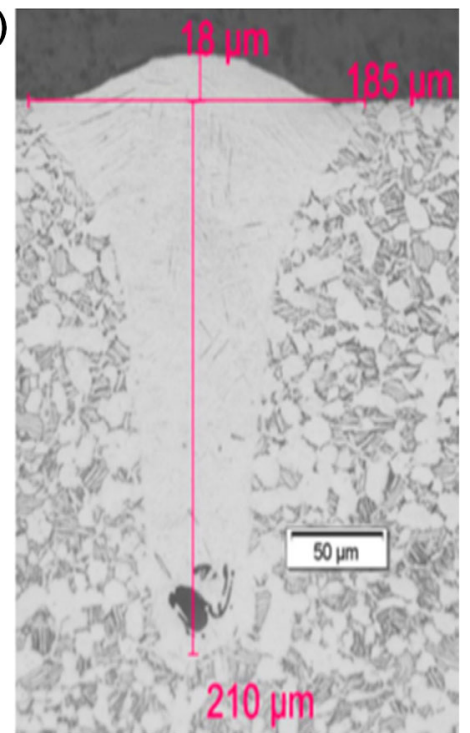

Fig. 1. (a) Heat-conduction mode. (b) Keyhole dominant mode.

The influence of the powder layer on energy coupling was studied by comparing melt pool characteristics with and without a powder layer.

For all the experiments, the melt pool depth, height and width as well as the remolten surface have been evaluated. All single-track experiments were conducted on Ti6Al4V substrate.

\section{Process Parameter: Scan Speed, Laser Power}

Starting from the default parameter set (red circle in Fig. 2), ten different combinations of laser power and scanning velocity are used. Figure 2 shows the line energy as a contour plot for the different process parameters. With increased line energy, more keyholing is expected.

\section{Powder Layer}

The single-track studies were performed with either no powder or with two different layer thicknesses: $h_{\mathrm{L}} 30$ and $60 \mu \mathrm{m}$. The powder layers were manually applied with a scraper with the corresponding gap height. To increase the flowability, the powder was applied in an ethanol suspension (volume weighted $50 \%$ powder, $50 \%$ ethanol). The applied powder layer thickness was measured using an infinity focus microscope and found to be roughly $5 \mu \mathrm{m}$ higher than the gap height, resulting in layer thicknesses of $h_{\mathrm{L}} \approx 35 \mu \mathrm{m}$ and $65 \mu \mathrm{m}$.

\section{Beam Diameter}

To vary the laser beam diameter (based on $86 \%$ definition), two different SLM machines with beam diameters of $d_{\mathrm{LEOS}}=80 \mu \mathrm{m}$ and $d_{\mathrm{LILT}}=110 \mu \mathrm{m}$ were used. The process parameters from the ILT laboratory machine were transferred to the EOS

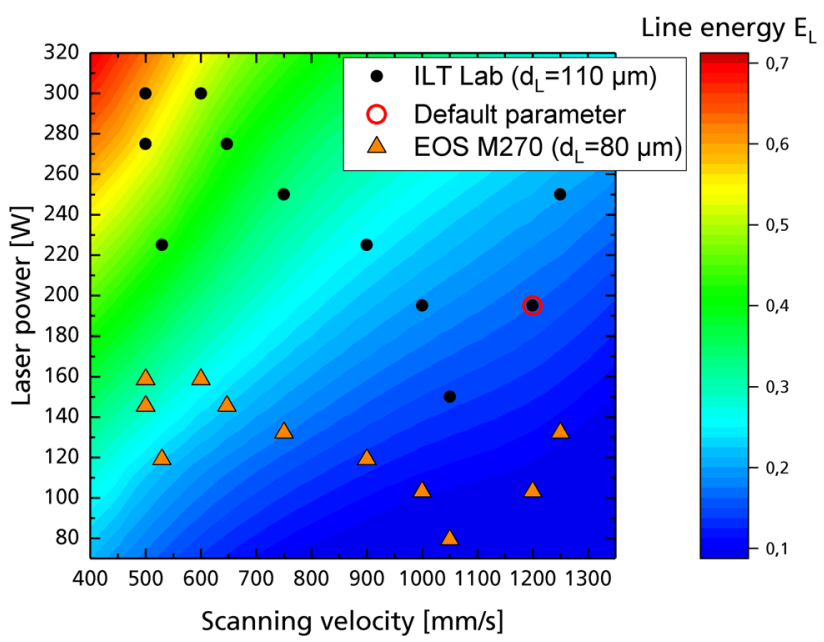

Fig. 2. Parameter combinations for laser power and scanning velocity for the two different laser beam diameters $d_{\mathrm{L}}$. The background color represents the relative line energy in relation to the default parameter (red circle).

machine by keeping the average laser beam intensity and scanning velocity constant. The laser power $P_{\text {LEOS }}$ was adapted accordingly:

$$
\frac{P_{\mathrm{LILT}}}{\pi d_{\mathrm{LILT}}^{2}}=\frac{P_{\mathrm{LEOS}}}{\pi d_{\mathrm{LEOS}}^{2}}=\mathrm{constant}
$$

\section{Analysis}

The fabricated single-track samples were cut perpendicular to the scanning direction. The crosssection was polished and etched with Kroll's reagent (duration: $30 \mathrm{~s}$ ). The melt pool boundaries were visualized using a light microscope. The depth (substrate level to deepest melting point), height (highest remolten material point to substrate level), width (width of melt pool on substrate level) and surface (integrated area of molten material in crosssection) were measured.

\section{Melt Pool Monitoring: High Speed Videogra- phy}

Extracting the length of a melt pool using micrographs is time consuming and error-prone. To obtain the melt pool length, we used high speed videography. The melt pool width measured by videography was verified using single-track measurements. Other information like the size of powder denudation zone and particle movement in the process zone could also be observed, but were not part of this work.

The videos were recorded with a Photron FastCam SA-5 and additional pulsed diode lasers $(\lambda \approx 800 \mathrm{~nm})$ were used to illuminate the process zone. The wavelength of the process laser $(\lambda=1064 \mathrm{~nm}) \quad$ was filtered out to avoid 
overexposure. The spatial resolution of the video material was gauged by recording single tracks with a defined hatch spacing. The achieved resolution was $9.31 \pm 0.06 \frac{\mu \mathrm{m}}{\mathrm{px}}$. The frame rate was $75 \mathrm{kHZ}$.

\section{NUMERICAL MODELS}

The software package ESI-AM was used throughout this study for both powder-scale and workpiece analysis. Using a discrete element model to obtain the powder bed characteristics, Mindt et al. showed how the balance between powder size distribution

Table I. Process parameters used for bridge build

\begin{tabular}{lc}
\hline Laser power $(\mathrm{W})$ & 175 \\
Scan speed $(\mathrm{m} / \mathrm{s})$ & 1.2 \\
Hatch spacing $(\mu \mathrm{m})$ & 80 \\
Layer thickness $(\mu \mathrm{m})$ & 30 \\
Stripe width $(\mu \mathrm{m})$ & 500 \\
Layer rotation $\left(^{\circ}\right)$ & 90 \\
\hline
\end{tabular}

and the slit height can affect the coating quality and powder recyclability. ${ }^{9,10}$ The numerically obtained powder bed was transferred to the melting models to solve Navier-Stokes equations as described in Ref. 6. The mechanical analysis was assumed weakly coupled to the thermo-metallurgical phenomena. ${ }^{11}$ The non-linear material behavior was accounted for by using a quasi-static incremental analysis. ${ }^{12-14}$

Ti6Al4V properties reported in the literature were used. ${ }^{15-20}$

\section{DEMONSTRATION COMPONENT}

A bridge geometry was chosen as a demonstrator component because of the relative ease of quantifying the bridge curvature (BC). ${ }^{21}$ Table I summarizes the process parameters used.

To increase stress and strain, no preheating was used. The specimens were removed force-free from the base plate by EDM. Since the pillars are not held in place any more, the residual stresses inside
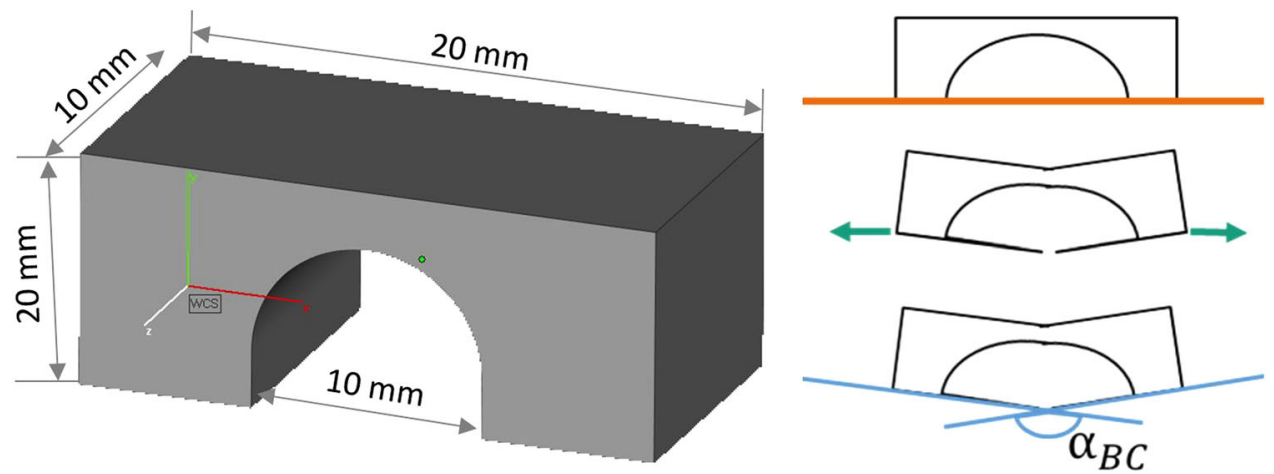

Fig. 3. Bridge geometry used for distortion analysis and BC analysis: cutting (orange), the inherent stress and strain lead to distortion (green), the measurement of the angle $\alpha_{B C}$ (blue).
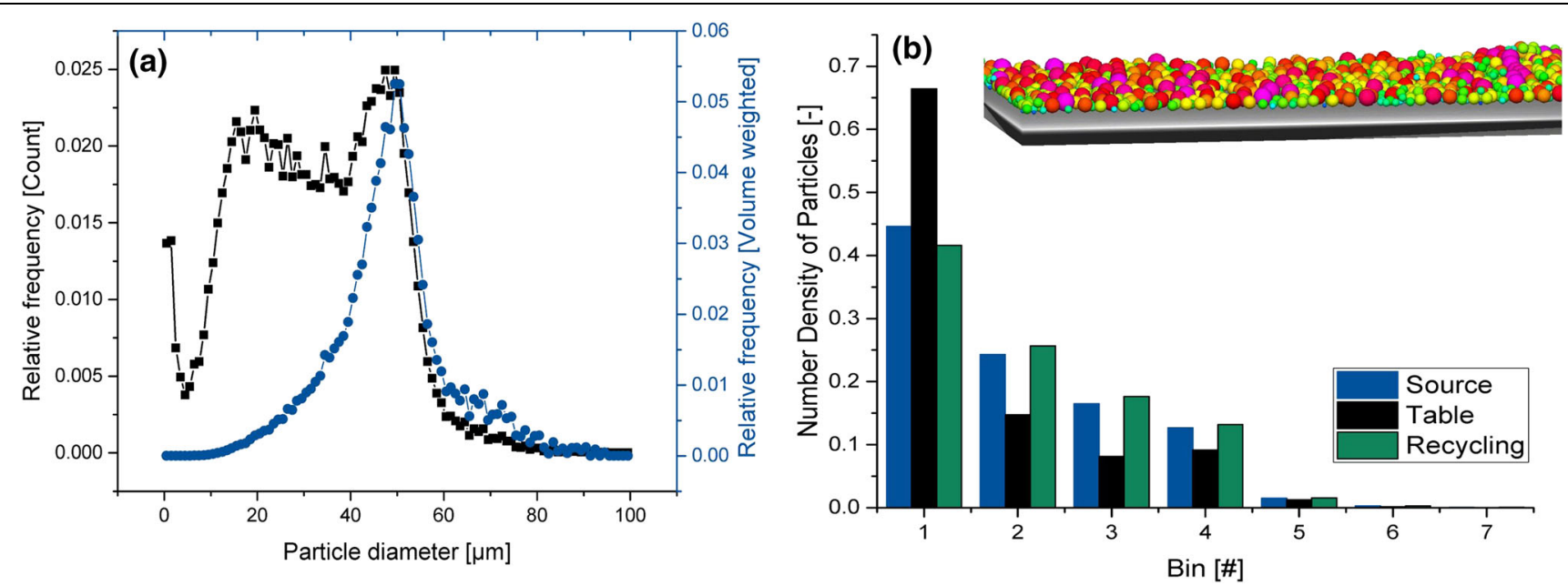

Fig. 4. (a) Volume and amount weighted particle size distribution of utilized Ti6AIV4 powder. (b) Corresponding numerical powder bed and recyclability assessment. 
the material leads to a distortion. The angle $\alpha_{\mathrm{BCM}}$ between the bridge pillars was then measured with a 3D scanner (GOM) (Fig. 3).

\section{RESULTS AND DISCUSSION}

\section{Powder Characterization}

The powder chemical composition was analyzed, confirming compliance with Ti6Al4V specifications. The particle size distribution was analyzed using an automated particle measuring system (Morphologi G3). It was found to correspond to the recommended particle diameters of $d_{\mathrm{p}}=20-63 \mu \mathrm{m}$. The particle size distribution is shown in Fig. 4; it serves as input for powder-coating simulations. A numerical assessment of powder recyclability was performed using the models described in Ref. 10. Figure 4 compares the number density of powder fractions in fresh powder (source) with those of the powder deposited on the processing table and the powder in the recycling bin. Powder particles with the smallest diameters deposit readily on the processing table. Larger powder sizes deposit proportionally to the provided volume fraction. By considering the predicted mass fraction in the recycling bin, it can be expected that the powder will tend slightly to larger particle sizes when recycled. An example of numerically obtained powder beds used for melting analysis is also presented.

\section{Single Track Studies}

Figure 5 shows typical results for melt pool modeling. The images compare melt pool isometric and side views for exemplary conduction (a) and

(a) $\mathrm{P}_{\mathrm{L}}=103 \mathrm{~W} \mathrm{v_{ \textrm {s } }}=1200 \frac{\mathrm{mm}}{\mathrm{s}}$

(b) $P_{\mathrm{L}}=145 \mathrm{~W} \mathrm{v}_{\mathrm{s}}=647 \frac{\mathrm{mm}}{\mathrm{s}}$

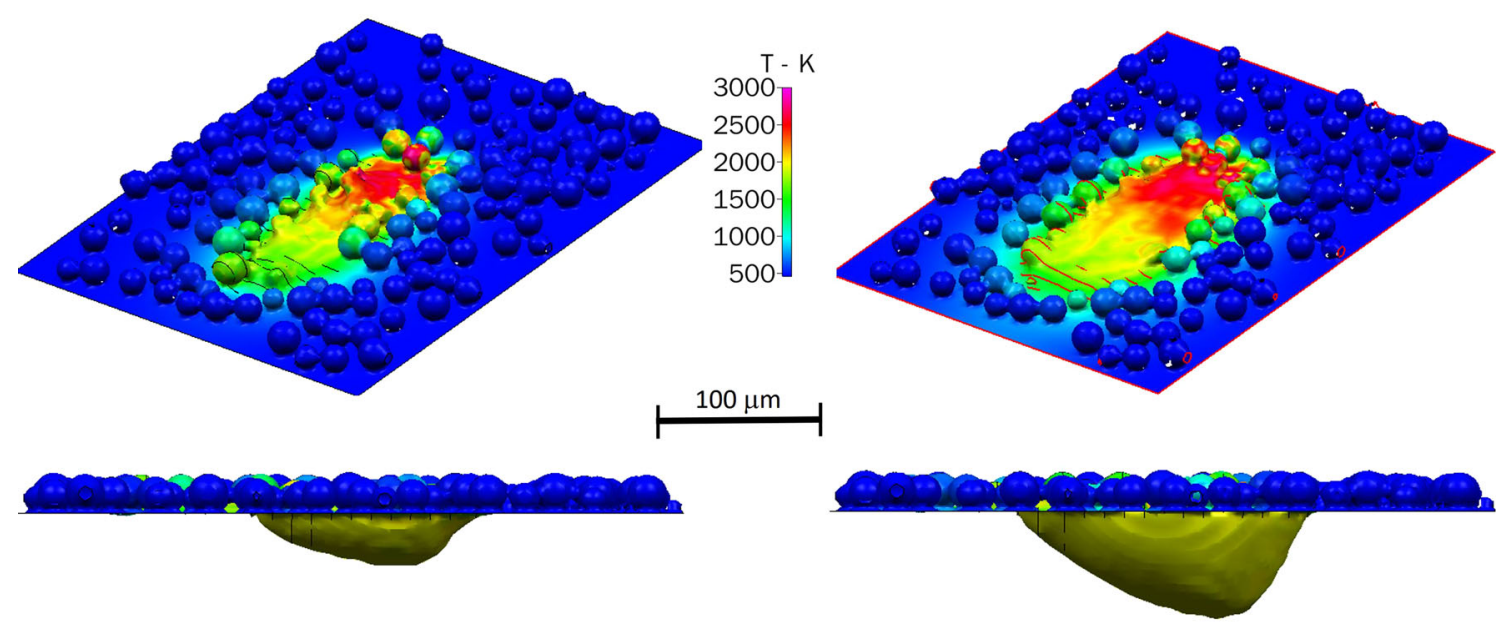

Fig. 5. (a) Melt pool surface (top) and side view (bottom) colored by temperature for conduction mode. (b) Keyhole mode.
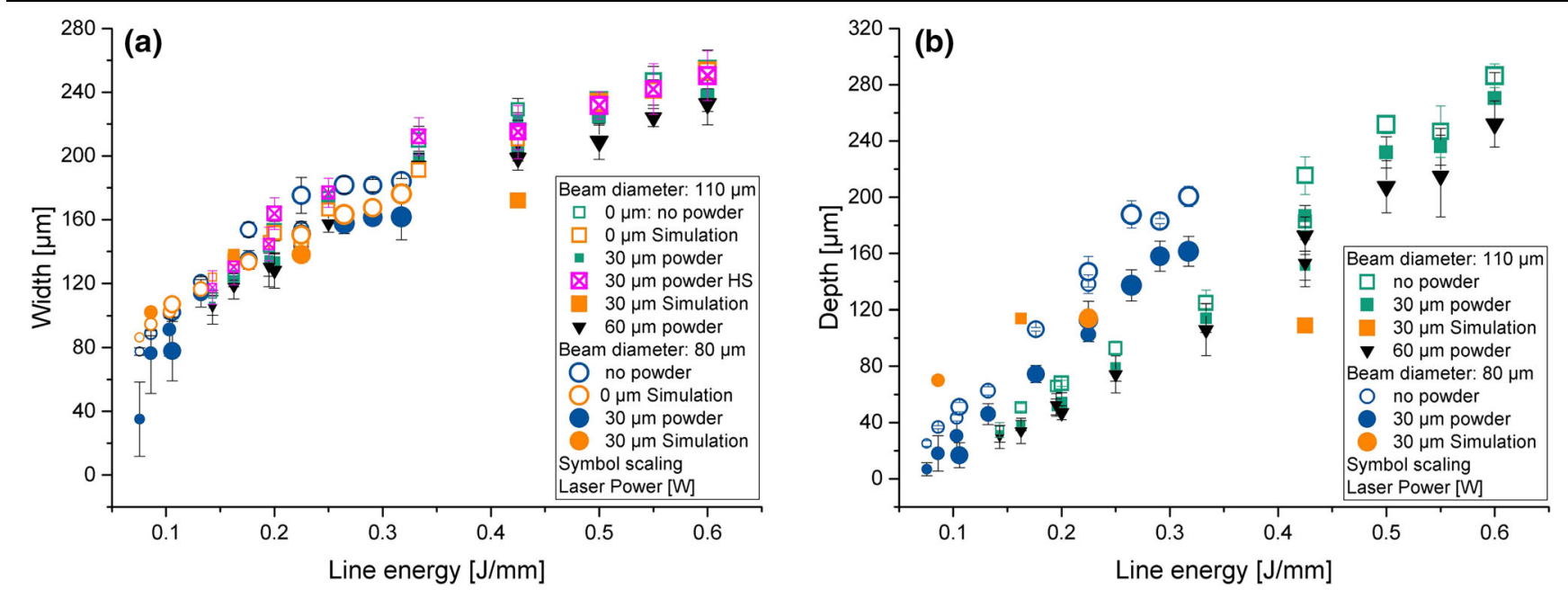

Fig. 6. Experimental and numerical melt pool width (a) and depth (b) as function of line energy. 
keyhole conditions (b). The contour plot depicts the temperatures. The peak temperature is significantly higher than the melting temperature for both cases and remains slightly lower than the evaporation temperature due to the latent heat of evaporation. In the case of the conduction mode, evaporation mainly occurs on the surface of the melt pool. The side view shows that less than two layers will be remolten in the case of the conduction mode, whereas up to 4-5 layers will remelt in the case of keyholing.

Measured and predicted melt pool width and depth values are compared in Fig. 6. The width increases with line energy until a possible stable state (maximum width) is reached. The maximum width is roughly 2-2.5 times the beam diameter. Increasing the line energy after this point only increases the melt pool depth. The melt pool

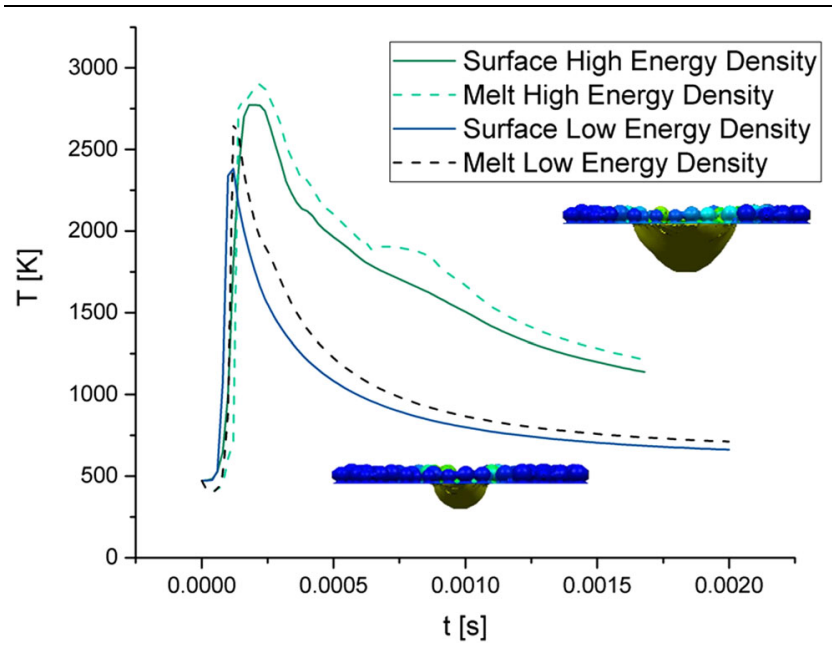

Fig. 7. Cooling rate comparision of two melt pools created using low and high line energy cases $\left(d_{\mathrm{L}}=80 \mu \mathrm{m}, h_{\mathrm{L}}=30 \mu \mathrm{m}, P_{\mathrm{L}}=103 \mathrm{~W}\right.$ and $145 \mathrm{~W}$ and $v_{\mathrm{s}}=1200$ and $647 \frac{\mathrm{mm}}{\mathrm{s}}$. width without powder is a little larger $(\approx 10 \mu \mathrm{m})$ than 'with powder', possibly due to additional particle mass sucked into the melt pool, effectively cooling the melt pool at its boundaries, thus slowing the outward expansion of the melt. Single-track melt pool width values have also been used to confirm the accuracy of high speed image processing; Fig. 6a shows excellent correlation between both methods for a $30-\mu \mathrm{m}$ powder layer thickness and beam diameter of $110 \mu \mathrm{m}$.

The melt pool depth increases linearly with increasing the line energy. Since the depth is measured from substrate level to the deepest point in the melt pool, the depth of the single tracks processed without powder is larger than the corresponding 'powder case' setup. Figure $6 \mathrm{~b}$ shows that the depth difference is roughly the height of the powder layer $h_{\mathrm{L}}=30 \mu \mathrm{m}$ and $60 \mu \mathrm{m}$.

Different beam diameters lead to different slopes of the depth-line energy curve. A smaller beam diameter, $d_{\mathrm{L}}$, results in a deeper melt pool (for the same line energy). The current working theory for this effect is that, for the small beam diameter, less energy is required to sustain a smaller (not so wide) keyhole leading to a more energy-efficient deep melting.

Numerical predictions of both the melt pool width and depth are within experimental accuracy for all cases, except of the case with a line energy $E_{\mathrm{L}}=0.42 \mathrm{~J} / \mathrm{mm}$, where the computational domain size was too small so that the boundary conditions were found to influence the result.

Figure 7 shows the thermal history at two monitor points on the track center line. One point is close to the melt pool surface and the other is directly below, near the melt pool base (conduction mode). The results for $0.53 \mathrm{~J} / \mathrm{mm}$ and $1.38 \mathrm{~J} / \mathrm{mm}$ are compared. The higher energy density leads to higher peak temperatures. The front view of the corresponding melt pool indicates keyholing. The cooling rate (peak temperature to solidus) for low
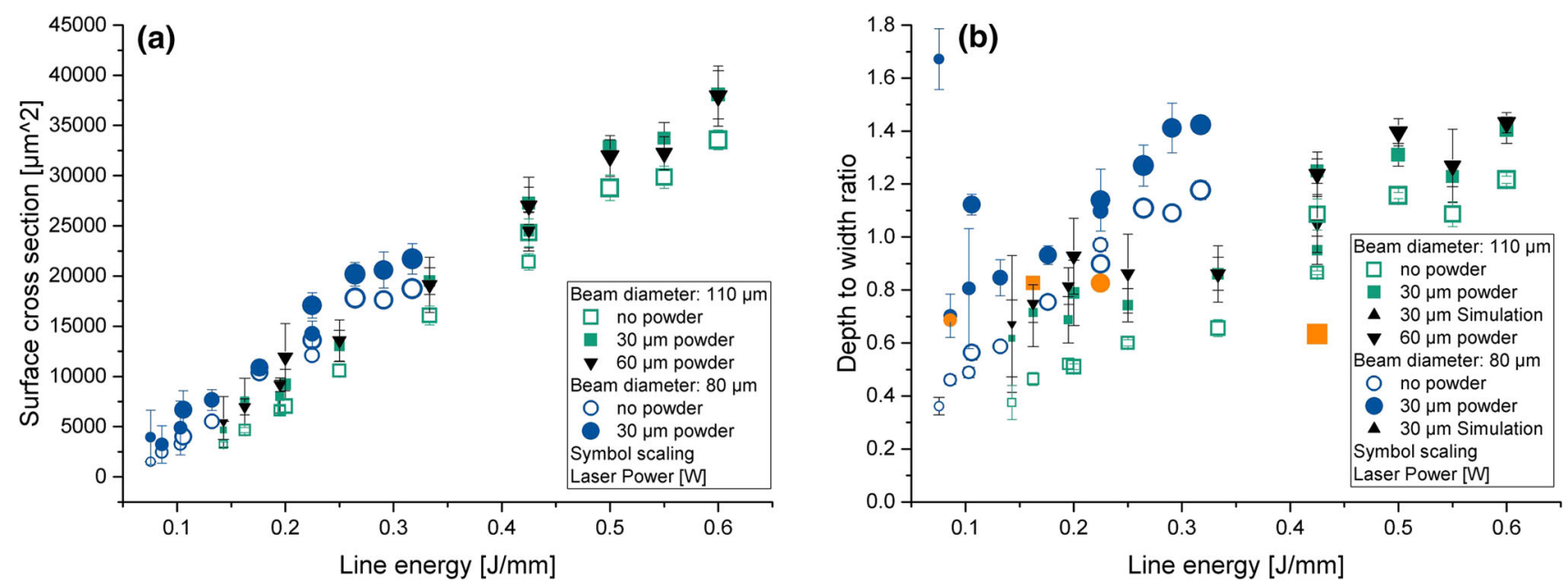

Fig. 8. (a) Surface area of molten material and (b) depth-to-width ratio as functions of line energy. 
and high energy densities are $6.3 \times 10^{6} \mathrm{~K} / \mathrm{s}$ and $2.27 \times 10^{6} \mathrm{~K} / \mathrm{s}$ respectively; which is comparable to the validated finding of IN718Plus. ${ }^{5}$ The difference in cooling rates is attributed to the difference in melt pool volume.

The surface of the remolten zone also increases with line energy (Fig. 8a). For the small beam diameter, the process seems to be more energy efficient. The depth-to-width ratio (Fig. 8b) for all cases increases linearly with line energy, but the slope for different beam diameters is different. The reason is that the melt pool width strongly depends on the beam diameter, while the depth depends mostly on the beam power.

Figure 9 shows the melt pool length extracted from high-speed videos compared with the values obtained from simulations. From the videos, it can be seen, that the melt pool length fluctuates strongly, resulting in a large statistical error.

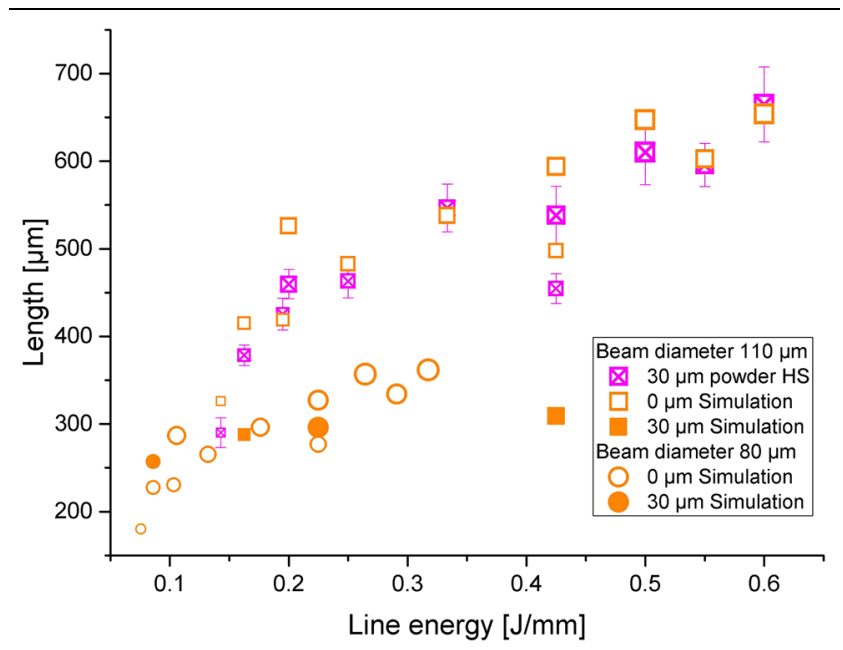

Fig. 9. Comparison of melt pool length determined from single-track analysis, high-speed videography and numerically.
Nevertheless, the melt pool length in the simulations is only underestimated by up to $75 \mu \mathrm{m}$, fitting very well with the measured data.

\section{Material Consolidation}

The process parameters are varied using an evolutionary optimization scheme. Two optimization objectives are defined: maximizing material density and maximizing deposition rate (defined as the mass of deposited material per unit time). Figure 10a shows the optimization results (pareto front) that compares the performance of approximately 1800 cases. Each case represents a combination of process parameters including laser power, scan speed, table displacement and hatch spacing. The density (described by a dimensionless factor) and the deposition rate are inversely proportional to one another. The leftmost point of the density curves is chosen for the maximum density achievable and a point after the increase in deposition rate is chosen for a quicker deposition option. The corresponding combination of process parameters is listed for both points. Process window optimization was also pursued experimentally and it was found that a preheat of $200^{\circ} \mathrm{C}$ is necessary to ensure a stable, crack-free process. Figure $10 \mathrm{~b}$ shows the consolidated material density as a function of line energy for two different power levels. Both the numerical and experimental optimization efforts yield similar process parameter combinations. The experimental optimum is used to manufacture the bridge specimens.

\section{Distortion and Residual Stresses}

Figure 11 shows the maximum vertical displacement for each layer. Given the chosen table displacement $(30 \mu \mathrm{m})$ and the predicted powder packing density, the available gap between build surface and coater arm is estimated to be
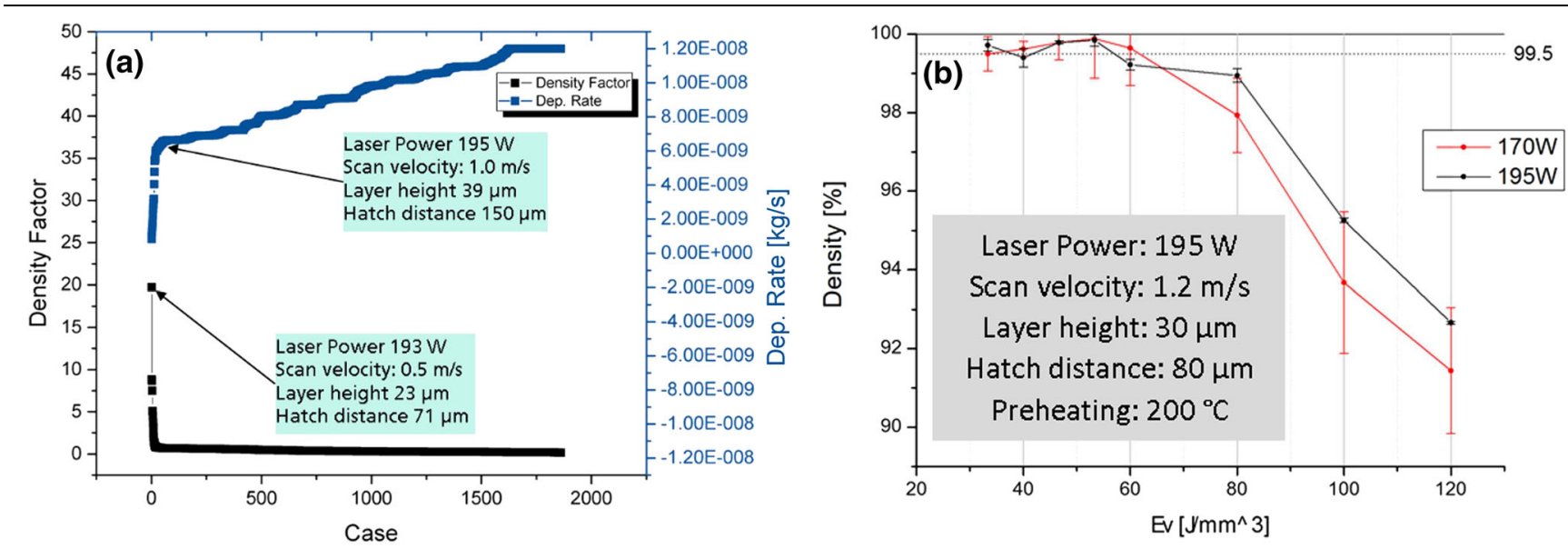

Fig. 10. (a) Pareto front for maximization of material density and depsosition rate. (b) Measured material density vs. volume energy at $200^{\circ} \mathrm{C}$ preheating. 


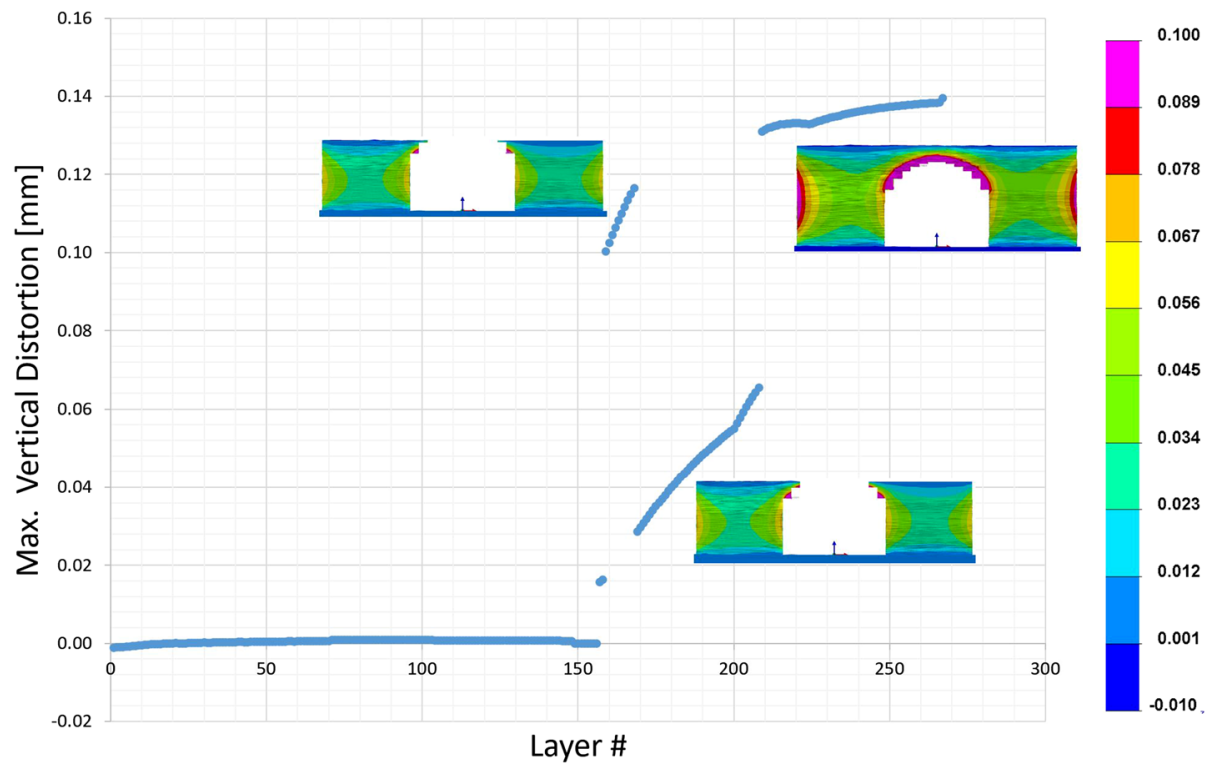

Fig. 11. Maximum vertical distortion for each layer.

Table II. Measured and predicted bridge curvature angle

\begin{tabular}{|c|c|c|c|c|}
\hline & Experiment & $\begin{array}{l}\text { Model lumping } 2 \\
\text { layers full layer } \\
\end{array}$ & $\begin{array}{c}\text { Model no lumping } \\
\text { full layer }\end{array}$ & $\begin{array}{l}\text { Model no lumping } \\
\text { resolved deposition } \\
\end{array}$ \\
\hline Average angle $\left(^{\circ}\right)$ & $178.84 \pm 0.07$ & 175.76 & 176.22 & 176.85 \\
\hline Error (\%) & - & 1.7 & 1.5 & 1.2 \\
\hline CPU (h) & - & 0.25 & 5 & 16 \\
\hline
\end{tabular}

approximately $70 \mu \mathrm{m}$. When the bridge arch is built (after layer $\sim 150$ ), the vertical distortion is larger than $70 \mu \mathrm{m}$ and the coater arm is expected to significantly interact with the build. Premature abortion of the job was avoided by using a soft coater arm. Six specimens were built to determined average curvature angle $\alpha_{\mathrm{BC}}=178.84^{\circ}$. Three models were pursued with different levels of fidelity: full layer with a layer thickness corresponding to 2 printed layers $(2 \times$ lump), full layer with a layer thickness corresponding to the printed layer thickness $(1 \times$ lump)and a high-resolution model, where the deposition strategy is fully resolved.

Table II summarizes the results, indicating a numerical error of $1.5 \%$. The balance between accuracy and speed of computation is in line with studies reported in Ref. 22. The remaining discrepancy is expected to reflect the accuracy of the material behavior model used.

\section{CONCLUSION AND SUMMARY}

Powder bed fusion process models were validated using single-track experiments. Different laser beam diameters and powder layer thicknesses were analyzed, showing that large spot sizes lead to wider and shallower melt pools. Model predictions were accurate for both conduction and keyhole modes. Numerical optimization of the TiAl6V4 processing window was successful, reducing the necessary experimental effort. Material density of up to $99.5 \%$ was achieved. The numerical chain was extended to determine the bridge curvature with $1.5 \%$ error. The study confirms that numerical models can be used throughout the process chain. Future work will apply the verified work flow to industrial components.

\section{ACKNOWLEDGEMENTS}

The authors acknowledge the financial support of European Union's Horizon 2020 research and innovation program under Grant Agreement 690725.

\section{OPEN ACCESS}

This article is distributed under the terms of the Creative Commons Attribution 4.0 International License (http://creativecommons.org/licenses/by/4.0/), which permits unrestricted use, distribution, and reproduction in any medium, provided you give appropriate credit to the original author(s) and the source, provide a link to the Creative Commons license, and indicate if changes were made. 


\section{REFERENCES}

1. I. Yadroitsev, Selective Laser Melting Direct Manufacturing of 3D-Objects by Selective Laser Melting of Metal Powders, 1st ed. (Saarbrücken, Germany: LAP Lambert Academic Publishing, 2009).

2. A.D. Peralta, M. Enright, M. Megahed, J. Gong, M. Roybal, and J. Craig, IMMI (2016). doi:10.1186/s40192-016-0052-5.

3. M. Vogel, M. Khan, J. Ibara-Meding, A. Pnkerton, N. N'Dri and M. Megahed, 2nd World Congress on ICME, 231 (2013).

4. N. N'Dri, H.-W. Mindt, B. Shula, M. Megahed, A. Peralta, P. Kantzos and J. Neumann, TMS, (2015). doi:10.1007/9783-319-48127-2_49.

5. H.-W. Mindt, M. Megahed, B. Shula, A. Peralta and J. Neumann, AIAA, (2016). doi:10.2514/6.2016-1657.

6. M. Megahed, H.-W. Mindth, N. N'Dri, H. Duan, and O. Desmaison, IMMI (2016). doi:10.1186/s40192-016-0047-2.

7. H.-W. Mindt, O. Desmaison, M. Megahed, A. Peralta, and J. Neumann, J. Mater. Eng. Perform. (2017). doi:10.1007/ s11665-017-2874-5.

8. J. Zhou, H.-L. Tsai, and P.-C. Wang, Trans ASME (2006). doi:10.1115/1.2194043.

9. A.B. Pierings and G. Levy, $S F F$ (2009).

10. H.-W. Mindt, M. Megahed, N.P. Lavery, M.A. Holmes, and S.G.R. Brown, Metall. Mater. Trans. A (2016). doi:10.1007/ s11661-016-3470-2.

11. E.R. Denlinger, J.C. Heigel, and P. Michaleris, Proc. Inst. Mech.Eng. B J. Eng. (2014). doi:10.1177/0954405414539494.
12. J. Carmet, S. Debiez, J. Devaux, D. Pont and. J.B. Leblond, International Conference on Residual Stresses (1989).

13. J.M. Bergheau and J.B. Leblond, Minerals Metals and Materials Society, 203 (1991).

14. B. Souloumaic, F. Boitout, and J.M. Bergheau, Mathematical Modelling of Weld Phenomena 6, ed. H. Cerjak (London: Maney, 2002), p. 573.

15. E. Attar, Simulation der selektiven Elektronenstrahlschmelzprozesse (Erlangen: University of ErlangenNuremberg, 2011).

16. K.C. Mills, Recommended values of thermophysical properties for selected commercial alloys (Cambridge England: Woodhead Publishing Limited, 2002).

17. I. Egry, D. Holland-Moritz, E. Ricci, R. Wunderlich, and N. Sobczak, Int. J. Thermophys. 31, 949 (2010).

18. A.N. Arce, Thermal Modeling and Simulation of Electron Beam Melting for Rapid Prototyping of Ti6Al4V (Raleigh: North Caroline State University, 2012).

19. Z. Zhang, Modeling of Al Evaporation and Marangoni Flow in Electron Beam Button Melting of Ti-6Al-4V (Vancouver: The University of British Columbia, 2013).

20. A. Klassen, T. Scharowsky, and C. Körner, J. Phys. D Appl. Phys. (2014). doi:10.1088/0022-3727/47/27/275303.

21. J.P. Kruth, J. Deckers, E. Yasa, and R. Wauthle, Proc. Inst. Mech. Eng. B J. Eng. (2012). doi:10.1177/0954405412437085.

22. O. Desmaison, P.-A. Pires, G. Levesque, A. Peralta, S. Sundarraj, A. Makinde, V. Jagdale and M. Megahed, 4th World Congress on ICME (2014). doi:10.1007/978-3-31957864-4_34. 